\title{
Modelling Yield and Seasonal Soil Salinity Dynamics in Rice-Grasspea Cropping System for the Coastal Saline Zone of West Bengal, India ${ }^{+}$
}

\author{
Sukamal Sarkar 1,*, Donald S Gaydon 2, Koushik Brahmachari 1, Manoj Kumar Nanda ${ }^{3}$, \\ Argha Ghosh ${ }^{3}$ and Mohammed Mainuddin ${ }^{4}$ \\ 1 Department of Agronomy, Bidhan Chandra Krishi Viswavidyalaya, Mohanpur 741252, India; \\ brahmacharis@gmail.com \\ 2 CSIRO Agriculture and Food, Brisbane 4067, Australia; don.gaydon@csiro.au \\ 3 Bidhan Chandra Krishi Viswavidyalaya, Department of Agricultural Meteorology and Physics, \\ Mohanpur 741252, India; mknandabckv@rediffmail.com (M.K.N.); ghoshargha4@gmail.com (A.G.) \\ 4 CSIRO Land and Water, Canberra 2601, Australia; mohammed.mainuddin@csiro.au \\ * Correspondence: sukamalsarkarc@yahoo.com \\ + Presented at the third International Tropical Agriculture Conference (TROPAG 2019), Brisbane, Australia, \\ 11-13 November 2019.
}

Published: 4 April 2020

\begin{abstract}
Due to seasonal dry-season salt accumulation in the coastal saline zone (CSZ) of West Bengal, India, the cultivation of winter crops (following summer rice) is rare. To address this issue, field experiments were conducted over two years (2016-18) in the CSZ to study the feasibility of cropping system intensification through incorporating grass pea into the dominant rice-fallow rotation. The experiment was conducted in strip plot design with two factors namely, Factor A: Six dates of rice sowing (at one-week intervals-2nd week of June to 3rd week of July) and Factor B: Two land situations (Medium-upland and Medium-lowland). The experiment was simulated using APSIM (Agricultural Production Systems sIMulator) utilizing the APSIM-SWIM water balance module to understand the mechanisms of seasonal soil salinity dynamics and the associated crop responses. The results suggest that irrespective of land situation, early sown rice (2nd week of June) produces higher dry matter and yield compared to late sown crops. This early rice sowing also facilitated better subsequent grass pea performance, by avoiding the worst of the salinity build-up and drought stress later in the winter. The model performed well in simulating the observed rice and grass pea yields ( $\mathrm{R}^{2}=0.97$ with low bias (slope, $\alpha=0.93$, intercept, $\beta=149 \mathrm{~kg} \mathrm{ha}^{-1}$ ), RMSE $=558$ $\mathrm{kg} \mathrm{ha}^{-1}$ ). It may be concluded that ASPIM-SWIM is an effective tool to understand, assess and predict the complex bio-physical mechanisms of ground water and soil salinity dynamics in ricepulse-based cropping systems of CSZ of West Bengal.
\end{abstract}

Keywords: APSIM; SWIM; salinity dynamics; coastal saline; pulses; cropping system

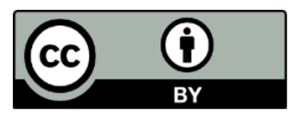

(C) 2020 by the authors. Licensee MDPI, Basel, Switzerland. This article is an open access article distributed under the terms and conditions of the Creative Commons Attribution (CC BY) license (http://creativecommons.org/licenses/by/4.0/). 